\title{
A novel template for anorectal fistula reporting in anal endosonography and MRI - a practical concept
}

\author{
Iwona Sudoł-Szopińska1,2, Małgorzata Kołodziejczak ${ }^{3}$, Santoro Giulio Aniello ${ }^{4}$ \\ ${ }^{1}$ Department of Radiology, National Institute of Geriatrics, Rheumatology and Rehabilitation, Warsaw, Poland, \\ ${ }^{2}$ Department of Diagnostic Imaging, Warsaw Medical University, Poland, ${ }^{3}$ Department of Proctology, St. Elizabeth \\ Hospital, Warsaw, Poland, ${ }^{4}$ Pelvic Floor Unit, Department of General Surgery, Regional Hospital, Treviso, Italy
}

\begin{abstract}
Anorectal fistula surgery is associated with risks of recurrence and/or faecal incontinence due to anal sphincter injuries. In order to minimise these complications, preoperative evaluation of the anatomy of the fistula tract and morphology of the anal sphincters is mandatory. Anal endosonography (AES) and Magnetic Resonance Imaging (MRI), due to high resolution of images and ability to identify a number of fistula elements which are important for surgeons in treatment planning, are the methods of choice in the diagnosis of anorectal fistulas.

In this paper, a new template for endosonographic and MRI report, systematically describing all anorectal fistula's characteristics, is presented. This template provides practical information for the surgeon, useful in preoperative assessment and postoperative follow-up.
\end{abstract}

Keywords: anal sphincter injuries; anorectal fistula; anal endosonography; magnetic resonance imaging

\section{Introduction}

Anal fistula is an abnormal connection between the anal canal and the anoderma or perianal skin, in the form of a tract lined with granulation tissue [1]. It is diagnosed in 8.6 to 10 per 100,000 individuals, $2-4$ times more frequently in males than in females [2-4]. Surgery for complex fistulas is associated with risks of recurrence and/ or faecal incontinence due to anal sphincter injuries. The

Received 17.08.2019 Accepted 07.10.2019

Med Ultrason

2019, Vol. 21, No 4, 483-486

Corresponding author: Iwona Sudoł-Szopińska

National Institute of Geriatrics,

Rheumatology and Rehabilitation,

1 Spartańskastreet, 02-637 Warsaw, Poland

E-mail: sudolszopinska@gmail.com decision when to cut, to tie, to plug or sew in order to maintain sphincter functionality and to limit the recurrence mostly depends on the preoperative accurate assessments of the several elements of the fistula by clinical examination and imaging [1].

Imaging modalities include anal endosonography (AES) and Magnetic Resonance Imaging (MRI). AES is commonly performed by a $360^{\circ}$ rotational probe with three-dimensional automatic acquisition [5]. MRI can be performed with an external or endorectal coil. Both techniques provide the visualization of the fistula anatomy and the evaluation of the morphology of the anal sphincters as well as the perianal and perirectal spaces (ischiorectal fossae and supralevator space), with MRI having the advantage due to a wider field of view, multiplanarity and ability to differentiate active tract with scar tissue on postcontrast images $[6,7]$. 
This manuscript presents a novel AES and MR template for anorectal fistula reporting, which can be used in clinical practice in managing patients with anal fistulas.

\section{Classifications of anorectal fistula}

The anorectal fistula classifications introduced by Park in 1976 includes four types of fistulas, according to the anatomy of the tract in relation to the anal sphincters [1,2,8]: 1) intersphincteric; 2) transsphincteric; 3) suprasphincteric and 4) extrasphincteric fistulas (fig 1).

The St. James University Hospital grading system designed by Morris et al in 2000, modified the Park's classification based on MRI of anorectal fistulas [1,2] to include abscesses and secondary extensions: grade 1: simple linear intersphincteric fistula; grade 2: intersphincteric fistula with intersphincteric abscess and secondary fistulous tract; grade 3: transsphincteric fistula; grade 4: transsphincteric fistula with an abscess and secondary
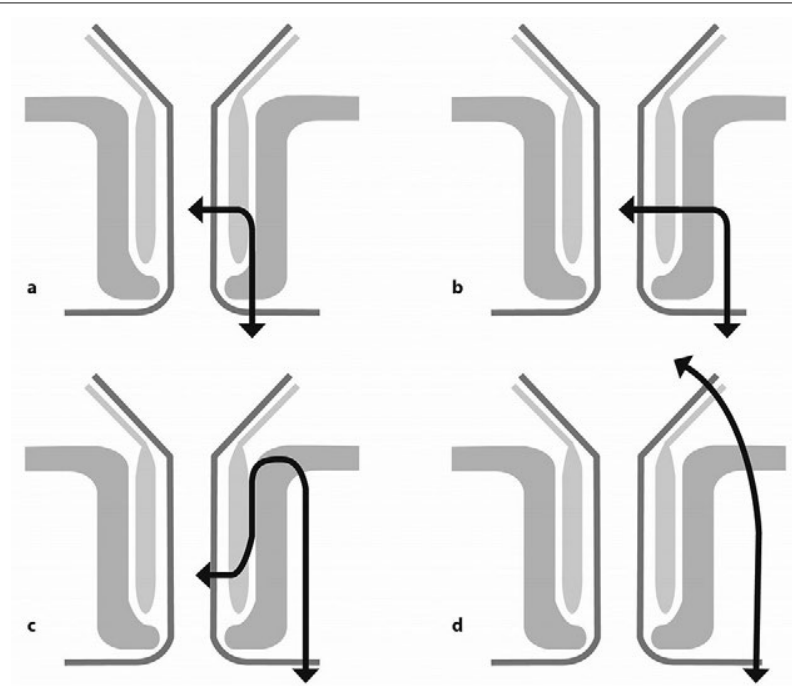

Fig 1. Four types of anal fistula according to Park's classifications: a) intersphincteric; b) transsphincteric; c) suprasphincteric; d) extrasphincteric

Table I. Anal endosonography and magnetic resonance imaging template for anorectal fistula report

\begin{abstract}
1. Fistula type according to Park's classification
2. Fistula localization based on the clockwise position
\end{abstract}

\section{Fistula height}

4. Secondary extensions

5. Location and patency and number of the internal openings

6. Residual abscess

7. Anal sphincters morphology

8. Schematic drawing
- Intersphincteric

- Transsphincteric

- Suprasphincteric

- Extrasphincteric

Location based on clockwise position (12 o'clock is anterior):

- Anterior (from 10 to 2 o'clock)

- Left lateral (from 2 to 4 o'clock)

- Posterior (from 4 to 8 o'clock)

- Right lateral (from 8 to 10 o'clock)

- Low ( $\leq 30 \%$ of EAS length)

- High ( $>30 \%$ of EAS length)

Location based on clockwise position (12 o'clock is anterior), including horseshoe:

- Intersphincteric, transsphincteric, extrasphincteric, suprasphincteric

Location based on clockwise position (12 o'clock is anterior)

Location based on clockwise position (12 o'clock is anterior), including horseshoe:

- Perianal

- Intersphincteric

- Ischiorectal

- Supralevator

- Multiple (please specify)

Regular, discontinuity, thinning, fibrotic degeneration:

- Internal sphincter

- External sphincter

- Puborectalis

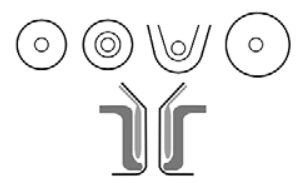


tract within the ischioanal or ischiorectal fossa; and grade 5: supralevator and translevator disease (incorporates suprasphincteric and extrasphincteric fistulas from the Park's classification), i.e. all fistulas above the levator ani.

Considering the above classifications, the following characteristics of the fistulas, crucial for the surgeon, are missing: 1) location of the fistulous tract (anterior, posterior, left/right lateral) and 2) how much external anal sphincter (EAS) is involved by the fistulous process.

Therefore, we propose a comprehensive novel template for AES and MRI anorectal fistula report (Table I), which includes:

1. fistula type according to Park's classification;

2. fistula localization in relation to the anal canal using the clockwise position, i.e. the description at which hour the fistula crosses the EAS [1];

3. fistula height; low fistula traverses $1 / 3$ of the EAS (i.e. the level at which only distal EAS is visible on axial AES and axial MRI scans); high fistula traverses more than $1 / 3$ of the EAS (i.e. the level at which the internal anal sphincter is visible medially to the EAS);

4. differentiation between simple (without secondary extensions) and complex (with secondary extensions) fistulas and determination of the number and location of the secondary tracts (ischiorectal, intersphincteric, supralevator, including the horseshoe tract), and site according to the clockwise position (anteriorly, posteriorly, or laterally) $[1,2]$;

5 . location and patency of the internal opening (or internal openings in presence of multiple fistulas);

6. description of a residual abscess, considering its type and location, according to the clockwise position (anteriorly, posteriorly, or laterally);

7. morphology of the anal sphincters (discontinuation, thinning, fibrosis) with information concerning the damage size (both level of the anal canal and how much circumference of the anal canal it involves);

8. schematic drawing of the anal canal enabling graphic presentation of the fistula course as well as its extensions by the reporting person.

In conclusion, the aim of the surgical treatment is to remove the fistula, minimizing the risk of recurrence and of injury to the anal sphincters. AES and MRI findings may influence the decision-making of anorectal fistulas, providing adequate information for the selection of the optimal surgical approach. The proposed template standardizes the report that radiologists should provide in the description of anorectal fistulas (fig 2).

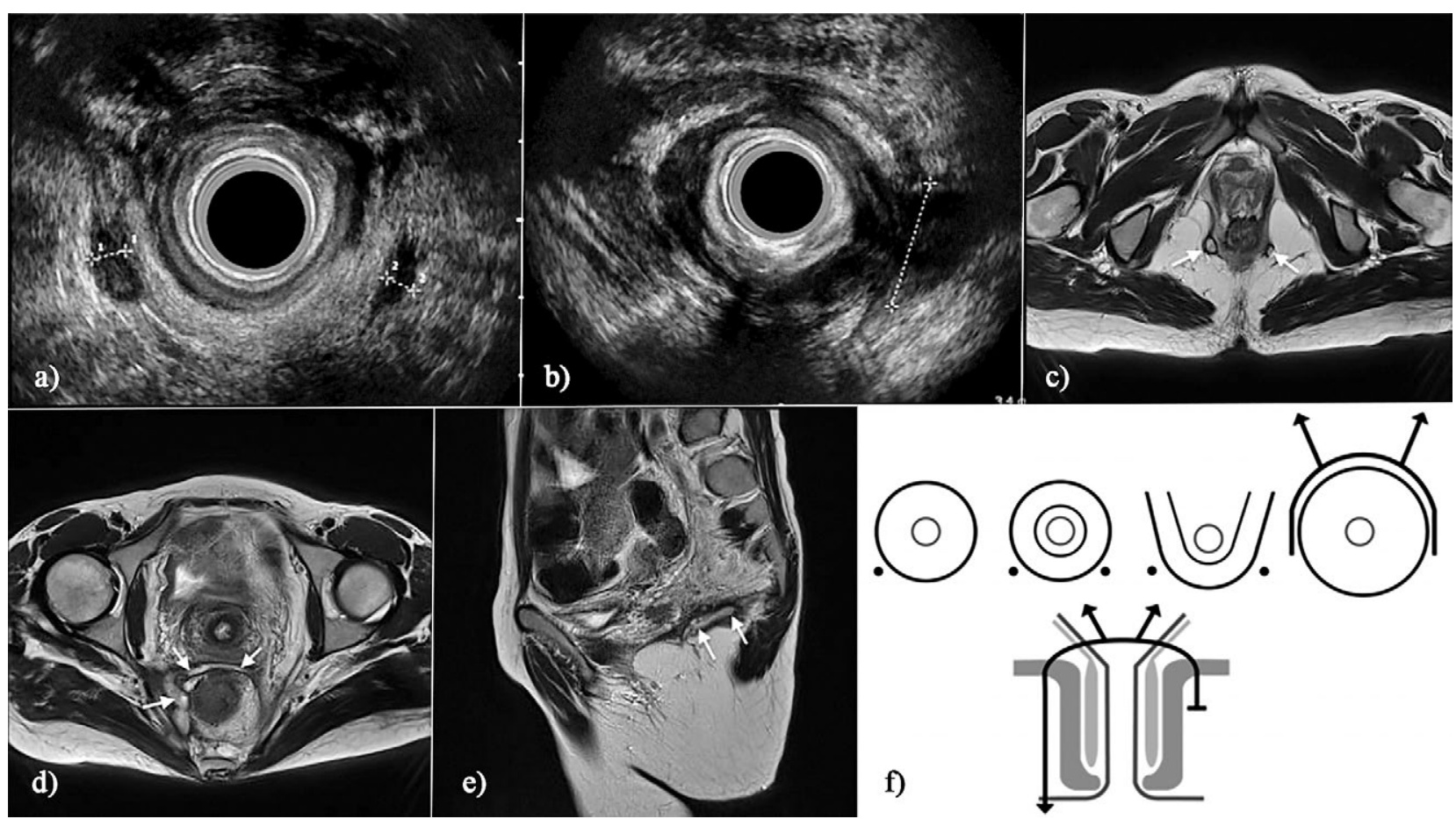

Fig 2. Extrasphincteric recurrent fistula in a 34-year-old female with Crohn Disease: a,b) AES; c,d) MR axial T2 Blade images; e) sagittal T2-weighted image; f) schematic drawing of the fistula tract. Fistula is seen (between crosses, arrows) in both ischiorectal-fossas $(a, c)$, crosses the right ramus of the puborectalis muscle (b; between crosses), and at $7 \mathrm{~cm}$ from the anal verge (d) it has an anterior, horseshoe, supralevator extension which crosses the midline and again goes down to the left ischiorectal fossa, where it ends blindly (a,c). An extension is seen on sagittal view (e), where it heads towards the sacrum. Anal sphincters are normal. 


\section{References}

1. de Miguel Criado J, del Salto LG, Rivas PF, et al. MR imaging evaluation of perianal fistulas: spectrum of imaging features. Radiographics 2012;32:175-194.

2. Morris J, Spencer JA, Ambrose NS. MR imaging classification of perianal fistulas and its implications for patient management. Radiographics 2000;20:623-635.

3. Torkzad MR, Karlbom U. MRI for assessment of anal fistulas. Insights Imaging 2010;1:62-71.

4. Sainio P. Fistula-in-ano in a defined population. Incidence and epidemiological aspects. Ann Chir Gynaecol 1984;73:219-214.
5. Santoro GA, Fortling B. The advantages of volume rendering in three-dimensional endosonography of the anorectum. Dis Colon Rectum 2007;50:359-368.

6. Kim MJ. Transrectal ultrasonography of anorectal diseases: advantages and disadvantages. Ultrasonography 2015;34:19-31.

7. Kołodziejczak M, Santoro GA, Obcowska A, Lorenc Z, Mańczak M, Sudoł-Szopińska I. Three-dimensional endoanal ultrasound is accurate and reproducible in determining type and height of anal fistulas. Colorectal Dis 2017; 19:378-384.

8. Bhaya AK, Kumar N. MRI with MR fistulogram for perianal fistula: a successful combination. Clin Gastrointest Magnetom 2007;1:156-159. 